\title{
Violent behavioral pathology and alcohol use among white male juvenile offenders in the United States
}

\begin{abstract}
The current study was designed to determine the extent to which self-reported alcohol use in a population of white male juvenile adolescent detainees in a southern state is associated with psychopathic violent problem behaviors. With this, the aim of this study is to examine distinctions, if any, between alcohol consumption and violent problem behavior outcomes among this population. Participants were 354 white male adolescent juvenile detainees extracted from an overall sample of 2260 juvenile offenders housed at selected Youth Development Campuses (YDCs) in the state of Georgia. Relationships between individual violent problem behavior variables and measures of alcohol use were examined using multiple linear regression models. Age first drinking alcohol significantly predicted and were associated with respondent's having previously threatening to beat someone up $(\beta=-.227, \mathrm{p}<0.01)$, hitting a parent or guardian $(\beta=-.205, \mathrm{p}<0.01)$, carrying a razor, knife or gun $(\beta=-.248, \mathrm{p}<0.01)$, and the use of physical force $(\beta=-.180, p<0.01)$, all as indicated at the $p<.001$. The relationship between alcohol use and the occurrence of violent problem behaviors is clear yet nuanced and complex. Since the frequency of having had more than five drinks in same day was observed as a statistically significant predictor of all violent problem behaviors examined, with respect to prevention, evidence-based efforts should include public health approach to risk reduction, since high levels of alcohol use are predictive of the development of psychiatric disorders later in adulthood.
\end{abstract}

Keywords: deficit hyperactivity disorder, pathology, psychiatric disorders, psychopharmacology, neuromaturation, antidepressants, antianxiety
Volume I Issue 4 - 2015

\author{
Torrance Stephens,' Rhonda Conerly \\ Holliday, ${ }^{2}$ Lamonte Powell C,, Unity Harris,' \\ Ronald Braithwaite, ${ }^{2}$
}

'Department of Psychology, Clark Atlanta University, Georgia ${ }^{2}$ Preventive Medicine, Morehouse School of Medicine, Georgia

\author{
Correspondence: Torrance Stephens, PhD, Department of \\ Psychology; Department of Political Science, Clark Atlanta \\ University, Atlanta, Georgia, Tel 4048808236 , \\ Email tstephensphd@gmail.com
} Received: October 22, 2015 | Published: November 27,
2015

\section{Introduction}

In the United States, there has been a recent increase on the rate of violence conducted by you white males including nationally recognized events such as the October shooting carried out at Umpqua Community College in Oregon, the Sandy Hook Elementary School shooting occurring on December 14, 2012, in Newtown, Connecticut and the mass shooting took place at Emanuel African Methodist Episcopal Church in downtown Charleston, South Carolina on the evening of June 17, 2015. Although data indicate that violent crime, overall, has remained stable over the past 15 to 20years in the United States, ${ }^{1}$ this observation does not hold, true for violent juvenile crime, which until recently has increased dramatically in all sectors of our society. ${ }^{2-4}$ There is also a significant body of research that demonstrates that diagnostic labels associated with violent behavior has been applied to clinically diagnosed conditions including but not limited to serious emotional disturbance, antisocial personality disorder, conduct disorder, oppositional defiant disorder and attention deficit hyperactivity disorder (ADHD). ${ }^{5-9}$ Aggressive and violent behavioral pathology comprises various neurobiological features and phenomenology which are influenced by anatomically and functionally distinct neural circuits. ${ }^{10}$ Thus, it appears reasonable that neural circuitries that affect emotional states, like the central serotonergic system, also affect the predisposition towards aggressive behaviors. ${ }^{10-16}$

In addition, inordinate studies have documented a consistent connection between alcohol use and violent behavior. ${ }^{17,18}$ This is particularly true with adolescent populations. Over the past several decades, empirical investigations have noted the association between alcohol consumption and violent problem behaviors during adolescence. ${ }^{19-21}$ Among adolescent's populations alcohol use and violent behavior has been demonstrated to include physical assault, fighting, using weapons, robbery, strong arming and inflicting physical bodily harm and injury upon others. ${ }^{19,21,22-26}$ Even recently, similar findings have been noted, asserting that alcohol use may have a direct effect on aggressive behavior among adolescents, and particularly on fighting and other non-physical aggressive overt actions. ${ }^{27,28}$ Consequently, the patterns of alcohol and drug use that emerge during adolescence are frequently considered as being important determinants of later substance use behavior and associated psychiatric co-morbidity. ${ }^{29-31}$ One reason for this is that it has been suggested that alcohol intoxication may be a causal factor in increasing violent behavior through its psychopharmacological effects on cognitive function. Some that support this contention have indicated that this is because alcohol intoxication can impair information-processing capacity that might, lead a person to overreact to perceived provocation resulting in the display of violent behavior. ${ }^{32}$ Thus, it is clear the role that alcohol use plays in violent behavior in adolescent population, but it is unclear to how these observations are prevalent and the level of their association in various adolescent population parameters such as white male juvenile offenders.

There is little if any information on rates of violence and alcohol consumption in samples of white male juvenile offenders. Much of the, epidemiologic assessment of factors associated with substance use and violent problem behaviors have consistently focused on other adolescent population parameters, typically large diverse samples or urban and minority youth. ${ }^{33-39}$ In addition, many examine specific types of violent behavior such as dating violence. ${ }^{37,40,41}$ Another point 
of consideration is that most research that looks at white adolescent populations with respect to alcohol use and violent behavior often is comparative in nature to other ethnic groups ${ }^{42-47}$ Moreover, to our knowledge, no studies have examined the extent to which specific alcohol use factors may influence specific violent problem behaviors, especially in a sample of white male adolescent juvenile offenders. The vast majority of investigations have been based on small clinical or regional samples, which may not be representative of the general population of incarcerated juveniles, tend to target ethnic minority groups. ${ }^{48}$ or examine adolescent offender populations in aggregate. ${ }^{49,50}$ They also suffer from small sample sizes, which limit considerations of other socio-demographic confounders (Table 1). Furthermore, most studies have examined association's one condition at a time instead of presenting a comprehensive profile on a range of indicators that might be associated with problem violent behaviors that may be specific to white male juvenile offenders singularly. While the findings of these studies represent important preliminary steps toward understanding the relationship between alcohol consumption and violent behavior among adolescents, additional information is needed to replicate and extend them. Therefore, within this context, the current study was designed to determine the extent to which self-reported alcohol use in a population of white male juvenile adolescent detainees in a southern state is associated with high-risk violent problem behaviors. With this, the aim of this study is to examine distinctions, if any, between alcohol consumption and violent problem behavior outcomes among this population.

Table I Demographic profile of study participants. Missing values not included $n=354$

\begin{tabular}{lll}
\hline Variable & $\mathbf{n}$ & $\mathbf{( \% )}$ \\
\hline Locked up before this time & & \\
Yes & 200 & -56.7 \\
No & 153 & -43.3 \\
Highest grade completed & & \\
$\qquad 6^{\text {th }}$ & 7 & -2 \\
$7^{\text {th }}$ & 35 & -9.9 \\
$8^{\text {th }}$ & 131 & -37.1 \\
$9^{\text {th }}$ & 107 & -30.3 \\
$10^{\text {th }}$ & 56 & -15.9 \\
$11^{\text {th }}$ & 15 & -4.2 \\
$12^{\text {th }}$ & 2 & -0.6 \\
Ever had even one drink of alcohol & & \\
Yes & 341 & -96.6 \\
No & 12 & -3.4 \\
\hline
\end{tabular}

\section{Methods}

Participants were 354 white male adolescent juvenile detainees extracted from an overall sample of 2260 juvenile offenders housed at selected Youth Development Campuses (YDCs) in the state of Georgia. Health Educators approached prospective participants within the first three days of being admitted into the facilities, presented them with an overview of the study, and asked them to participate. Respondents who agreed to take part in the study signed an assent form that gave members of the research team permission to contact their parents and/ or legal guardian for their approval for participation. Before study implementation, approval was obtained from the university and the Department of Juvenile Justice Institutional Review Boards.

\section{Measures}

Demographics: Participants reported their age, incarceration history, years of formal education, length of current incarceration and age first drank alcohol.

Alcohol use: Four items were employed to provide multiple indices for self-reported alcohol use. The first was an opened ended interval/ ratio scaled item that asked, "How old were you when you had your first drink?" Individuals who responded to this item were asked three subsequent questions: "During your life time how many times have you had at least one drink of alcohol (measured on scale from 1 to $6(1=1$ or 2 times, $2=3$ to 9 times, $3=10$ to 19 times, $4=20$ to 39 times, $5=40$ to 99 times and $6=100$ or more times); On how many days did you drink alcohol on the last month, before entering the YDC or detention center (measured on scale from 1 to $6(1=$ none, $2=1$ or 2 days in the last month, $3=3$ to 5 days in the last month, $4=6$ to 9 days in the last month, $5=10$ to 19 days in the last month and $6=20$ to 31 days in the last month); and "In the last month before entering the YDC or detention center, how often did you have 5 or more drinks in the same day" (measured on scale from 1 to 5 ( $1=1$ or 2 days in the last month, $2=3$ to 5 days in the last month, $3=6$ to 9 days in the last month, $4=10$ to 19days in the last month and 5=20 to 31 days in the last month) Participants with missing data were not included in the analysis.

Problem behaviors: Seven problem behaviors were examined which specifically referenced the threat and/or actual use of violence or physical force. Sample items included "Hit one of your parents or guardians", "use a club, knife or gun to get something from someone", "carried a razor, switchblade or gun with the intention of using it in a fight", "pulled a knife, gun or some other weapon on someone just to let them know you meant business", and "beat someone up so badly they probably needed a doctor" All items were prefaced with the lead: "In the three months before entering a detention center or YDC, did you All items were measured using a scale from 1 to 4 ( $1=$ never, $2=$ once or twice, $3=$ many times, $4=$ often).

\section{Analysis}

Data were examined with the use of SPSS software version 16.0. Descriptive statistics were employed to present a profile of the participant's demographic characteristics. Analysis Relationships between individual violent problem behavior variables and measures of alcohol use were examined using multiple linear regression models. All models specified self-reported violent problem behaviors as an outcome with selected alcohol use factors variables (age first used alcohol, frequency of alcohol use,) as predictor variables. All measures were entered independently into the estimated equations. To conform to the assumptions regarding that continuous variables in our study had multivariate normal distributions, non-normality was assessed in this study using the Mardia's test for multivariate normality. ${ }^{51}$ The resulting multivariate index was not significant providing statistical evidence for a normal distribution.

\section{Results}

Study participants ages ranged between 14 and 18years with a mean age of 15.7 years $(\mathrm{SD}=0.86)$. In general, respondents indicated 
an aggregate average of 25.2 days incarcerated prior to survey administration $(\mathrm{SD}=25.64)$. Nearly 57 percent $(56.7 \%, \mathrm{n}=200)$ reported being locked up prior to the current incarceration. Most participants reported the 8 th $(37.1 \%, \mathrm{n}=131)$ and 9 th $(30.3 \%, \mathrm{n}=107)$ grades being their highest grade of school finished at time of recent incarceration. The mean age for participants age of first using alcohol was $12.41(\mathrm{SD}=2.51)$ years of age.

Age first drank alcohol: Table 2 presents results of the linear regression analysis that examined whether the selected self-reported violent problem behaviors were associated with alcohol use measures among sample participants prior to their current incarceration. As shown, Age first drinking alcohol significantly predicted and were associated with respondent's having previously threatening to beat someone up $(\beta=-.227, \mathrm{p}<0.01)$, hitting a parent or guardian $(\beta=-$ $.205, \mathrm{p}<0.01)$, carrying a razor, knife or gun $(\beta=-.248, \mathrm{p}<0.01)$, and the use of physical force $(\beta=-.180, \mathrm{p}<0.01)$, all as indicated at the $\mathrm{p}<.001$. Age first drinking alcohol also was a significant predictor of having had pulled a knife or gun on someone and using a club or knife as a weapon (both p's $<0.03$ ), as well as beating someone up so bad they needed to see a doctor $(\mathrm{p}<0.07)$.

Table 2 Results of linear regression between violent problem behaviors and selected alcohol use items

\begin{tabular}{|c|c|c|c|c|c|}
\hline Dependent variable & Factor & $\mathbf{R}^{2}$ & Beta & t & $\mathbf{p}$ \\
\hline \multirow[t]{3}{*}{ Threaten to beat someone up } & Age $1^{\text {st }}$ Drank Alcohol & 0.052 & -0.227 & -4.22 & 0.001 \\
\hline & Lifetime at least one drink & 0.019 & 0.138 & 5.78 & 0.001 \\
\hline & How many times had 5 plus drinks & 0.015 & 0.124 & 2.98 & 0.003 \\
\hline \multicolumn{6}{|l|}{ Hit one of Your Parents } \\
\hline & Lifetime at least one drink & 0.02 & 0.092 & 1.41 & 0.158 \\
\hline & Days Drank Before Entering & 0.012 & 0.108 & 1.97 & 0.049 \\
\hline & How many times had 5 plus drinks & 0.049 & 0.221 & 2.94 & 0.004 \\
\hline \multicolumn{6}{|l|}{ Carry Razor or Gun } \\
\hline & How many times had 5 plus drinks & 0.022 & 0.149 & 3.6 & 0.001 \\
\hline \multicolumn{6}{|l|}{ Pull Knife or Gun on Someone } \\
\hline & Age $1^{\text {st }}$ Drank Alcohol & 0.027 & -0.163 & -3.01 & 0.003 \\
\hline & Lifetime at least one drink & 0.019 & 0.138 & 5.79 & 0.001 \\
\hline & Days Drank Before Entering & 0.019 & -0.136 & -4.58 & 0.001 \\
\hline & How many times had 5 plus drinks & 0.028 & 0.167 & 4.04 & 0.001 \\
\hline \multicolumn{6}{|c|}{$\begin{array}{l}\text { Beat Someone Up where they needed } \\
\text { to see a doctor }\end{array}$} \\
\hline & Lifetime at least one drink & 0.012 & 0.107 & 4.51 & 0.001 \\
\hline & Days Drank Before Entering & 0.012 & -0.11 & -3.69 & 0.001 \\
\hline & How many times had 5 plus drinks & 0.021 & 0.146 & 3.52 & 0.001 \\
\hline \multicolumn{6}{|l|}{ Use Club or Knife } \\
\hline & Age $1^{\text {st }}$ Drank Alcohol & 0.027 & -0.164 & -3.02 & 0.003 \\
\hline & Lifetime at least one drink & 0.019 & 0.139 & 5.86 & 0.001 \\
\hline & Days Drank Before Entering & 0.023 & -0.152 & -5.13 & 0.001 \\
\hline & How many times had 5 plus drinks & 0.02 & 0.142 & 3.41 & 0.001 \\
\hline
\end{tabular}


Life, times had at least one drink: Regression analysis revealed that this variable was strongly associated and correlated with all selfreported violent problem behaviors. More significant that all findings indicated that the propensity for violent behaviors increases with the higher number of times participants reported having at least one drink in their Life (all p's $<0.01$ ). However, with respect to each dependent variable, none of these factors accounted for more than approximately 2 percent in the variance in each regression model. Days Did You Drink Month Prior Incarceration: As detailed in Table 2, "how many days did you drink alcohol in the last month before respondents present incarceration drinking was observed as a significant correlate with respondent's having previously threatening to beat someone up $(\beta=-.110, \mathrm{p}<0.01)$, carrying a razor, knife or gun $(\beta=-.245, \mathrm{p}<0.01)$, and the use of physical force $(\beta=-.110, p<0.01)$, all as indicated at the $\mathrm{p}<.001$. Age first drinking alcohol also was a significant predictor of having had pulled a knife or gun on someone $(\beta=-.136, p<0.01)$, and using a club or knife as a weapon $(\beta=-.152, p<0.01)$ and as well as beating someone up so bad they needed to see a doctor $(\mathrm{p}<0.01)$. However, it was barely predictive of respondents hitting a parent or guardian $(p<0.49)$. How Often Did You Have Five or More Drinks in Same Day, Month Prior Incarceration: This measure was observed as a statistically significant predictor of all seven violent problem behaviors examined. It accounted for almost 5 percent of the variance associated with hitting a parent or guardian $\left(\beta=.221, \mathrm{p}<0.01, \mathrm{r}^{2}=0.49\right)$ and three percent associated with study participants self-reports of having had pulled a gun or knife on someone previously $(\beta=.167$, $\mathrm{p}<0.01, \mathrm{r}^{2}=0.28$ ).

\section{Discussion}

The objective of this investigation was determine the extent to various self-reported measures of alcohol use in a sample of white male adolescent juvenile offenders contributes and is associated with violent problem behavior occurrence. It was interesting to observe the magnitude of the effect with all violent problem behaviors observed in this investigation with respect to self-reported age first drinking alcohol. This finding suggest that the earlier onset of alcohol use, the more likely respondents displayed all of the behaviors, of which caring a razor, knife or gun was the strongest as indicated by computed t-test. Likewise, having had at least one drink in one's life time was predictive of all problem behaviors with the exception of reporting having hit one's parents or guardians, suggesting that behaviors associated with white male juvenile offenders violence towards parents may be attributable to other factors. Another inverse relationship was noted in terms of day's study participants drank before their current incarceration. It could be that the less they drank, under the expectation of going to an YDC, the more violent they behaved. Albeit all of the aforementioned is justified speculations, this investigation is important for several reasons. First, it will aid in providing a more complete descriptions of substance use among adolescents by looking at a specific ethnic subsection, a sample of white male offenders. Moreover we have provided support for other similar studies that assert the influence of alcohol in adolescent males having a high propensity to report alcohol-related violence. ${ }^{52}$ This is important on numerous levels, one of which being that frequent drinking and antisocial behavior have been documented of strong correlates of later alcohol dependence in adulthood as determined by the Diagnostic and Statistical Manual volume IV (DSM-IV). ${ }^{53}$

Longitudinal research studies indicate that adolescents that start drinking alcohol earlier are more likely than adolescents that start drinking later in life to increase use into early adulthood, ${ }^{54}$ have more lifetime impairment and social problems, ${ }^{55}$ have an elevated risk for developing drinking problems later in life, ${ }^{56}$ other issues of dependency and illicit substance use $\mathrm{e}^{57}$ and other negative outcomes that contribute to extended psychopathology. ${ }^{58}$ Consequently, prevention and early intervention initiatives to reduce longer-term alcohol-related harm need to address the factors that influence white male juvenile offenders alcohol consumption and high-risk drinking patterns, especially personal expectations of drinking as well as consequences due to alcohol consumption, in particular violent behavior, given that by some estimates, by age 20 , approximately $5 \%$ may meet alcohol dependence criteria and that alcohol dependence in adults has been shown to be preceded by higher persisting teenage rates of frequent drinking. ${ }^{59}$ Just as important is that as a consequence, of early alcohol use violent behavior in adolescents may eventually contribute to the increased likelihood of a range of future psychopathology. For example, Biederman and associates reported that extended and high rates of alcohol consumption may lead to significantly higher lifetime risk for psychoactive substance use disorders in adulthood, in particular those with ADHD, as well as higher rates of mood and anxiety disorders. ${ }^{60}$ Given that prior research has noted that among incarcerated adolescents, that the possibility of comorbidity of other psychiatric disorders in concert with conduct disorders and substance use may exit ${ }^{61}$ future studies should examine the rate to which to coexisting psychiatric disorders may or may not exist in other specific juvenile offender populations. In addition, interventions need to deal with the careful diagnosis and treatment of coexisting psychiatric disorders in incarcerated youths ${ }^{62}$ inclusive of using neuropsychiatric and psychoeducational assessments tools based on the empirical data. ${ }^{63,64}$

The results of this study must be understood in reference to several methodological limitations. In particular, that this investigation was implemented in juvenile detention centers as opposed to community settings, which may result in spurious findings when compared to the general adolescent population. An additional limitation may be related to the instrumentation. Self-report measures may lead to response bias, and there may be a need to develop more effective, accurate and sensitive screening tools regarding suicide ${ }^{65}$ Although we did employ self-report measures on health status, we feel that our sample size was random and large enough to validate the findings presented herein as with other studies examine relationships with substance use and problem behaviors among adolescent offender populations. ${ }^{66-68}$ Moreover, our results are only generalizable to white male adolescents who are institutionalized, a group that may be both at increased risk for interpersonal violence perpetration and more likely to reside in neighborhoods characterized by lower collective efficacy. However, studying adolescents incarcerated in YDCs provides a unique opportunity to assess risk behaviors associated with both alcohol consumption and violent problem behaviors.

\section{Conclusion}

In summary, the relationship between alcohol use and the occurrence of violent problem behaviors is clear yet nuanced and complex. Investigators concerned with problems affiliated with substance use, violence, incarceration and adolescent should continue to conduct more systematic investigation examination of associations among specific constellations of the progression of alcohol use behaviors among adolescent offenders and in the process, try and outline any additional temporal and potentially causal relations among alcohol use behaviors and any associated psychopathology affiliated with violent behavior in concert with distinct demographic 
and sociocultural characteristics. The findings herein underscore the critical importance of prevention and intervention strategies that reduce the occurrence, frequency, and impact of multiple types of adverse experiences that occur in white male, as well as other male juvenile offender population in outward manifestations of violent behavior as a function of alcohol use. With respect to prevention, significant and enduring impact for incarcerated adolescent populations should both be evidence-based and include support for a public health approach to risk reduction. Especially since clinical studies note that alcohol use during adolescence is associated with prefrontal volume abnormalities, including white matter differences, ${ }^{69}$ which some researchers have shown to be predictive of the development of psychiatric disorders later in adulthood given that neuromaturation continues into late adolescence. ${ }^{70-72}$ Lastly, it is imperative that future investigations explore alcohol use in concert with psychotropic drug use regarding violent behaviors given the causal relationship supported in the research with some antidepressants, antipsychotics, antianxiety agents and mood stabilizers with violent and aggressive behavior. $^{73-79}$

\section{Acknowledgements}

None.

\section{Conflict of interest}

The author declares no conflict of interest.

\section{References}

1. United states department of justice. Federal bureau of investigation. Crime in the United States; 2012.

2. Dahlberg LL. Youth violence in the United States: major trends, risk factors, and prevention approaches. Am J Prev Med. 1998;14(2):259-272.

3. Furlong MJ. Evaluating school violence trends. National School Safety Center News Journal. 1994;323-327.

4. US. Department of justice and US. Department of education. First annual report on school safety. Washington: DC; 1998.

5. Hinshaw SP. On the distinction between attentional deficits/hyperactivity and conduct problems/aggression in child psychopathology. Psychological Bulletin. 1987;101(3):443-463.

6. Lynam D. Early identification of chronic of fenders: Who is the fledgling psychopath? Psychological Bulletin. 1996;120(2):209-234.

7. Barkley RA, Fischer M, Smallish L, et al. Young adult follow-up of hyperactive children:antisocial activities and drug use. J Child Psychol Psychiatry. 2004;45(2):195-211.

8. Filley CM, Price BH, Nell V, et al. Toward an understanding of violence: neurobehavioral aspects of unwarranted physical aggression:Aspen neurobehavioral conference consensus statement. Neuropsychiatry Neuropsychol Behav Neurol. 2011;14(1):1-14.

9. Afifi TO, Mather A, Boman J, et al. Childhood adversity and personality disorders: Results form a nationally representative population-based study. Journal of Psychiatric Research. 2011;45(6):814-822.

10. Lesch K-P, Merschdorf U. Impulsivity, aggression, and serotonin: a molecular psychobiological perspective. Behav Sci Law. 2000;18(5):581604 .

11. Bradley R, Jenei J, Westen D. Etiology of borderline personality disorder disentangling the contributions of intercorrelated antecedents. The Journal of Nervous and Mental Disease. 2005;193:24-31.

12. Davison S, Janca A. Personality disorder and criminal behavior: What is the nature of the relationship? Current Opinion in Psychiatry. 2012;25(1):3945.

13. Johnson JG, Cohen P, Smailes E, et al. Adolescent personality disorders associated with violence and criminal behavior during adolescence and early adulthood. American Journal of psychiatry. 2005;157(9):1406-1412.

14. Frankle WG, Lombardo I, New AS, et al. Brain serotonin transporter distribution in subjects with impulsive aggressivity: a positron emission study with [11C] McN 5652. Am J Psychiatry. 2005;162(5):915-923.

15. Liao DL, Hong CJ, Shih HL, et al. Possible association between serotonin transporter promoter region polymorphism and extremely violent crime in Chinese males. Neuropsychobiology. 2004;50(4):284-287.

16. Retz W, Retz-Junginger P, Supprian T, et al. Association of serotonin transporter promoter gene polymorphism with violence: relation with personality disorders, impulsivity, and childhood ADHD psychopathology. Behav Sci Law. 2004;22(3):415-425.

17. Foran Hm, O’Leary Kd. Alcohol and intimate partner violence: A metaanalytic review. Clinical Psychology Review. 2008;28(7):1222-1234.

18. Klosterman Kc, Fals-Stewart W. Intimate partner violence and alcohol use: Exploring the role of drinking in partner violence and its implications for intervention. Aggression and Violent Behavior. 2006;11:587-597

19. White Hr, Hansell S. Longitudinal predictors of serious substance use and delinquency. Journal of Research in Crime and Delinquency. 1996;33:450-470

20. White $\mathrm{Hr}$, Hansell S. Acute and long-term effects of drug use on aggression from adolescence into adulthood. Journal of Drug Issues. 1998;28(4):837_ 858

21. White Hr, Brick J, Hansell S. A longitudinal investigation of alcohol use and aggression in adolescence. Journal of Studies on Alcohol, Supplement. 1993;11:62-77.

22. White Hr, Loeber R, Stouthamer-Loeber M, et al. Developmental associations between substance use and violence. Development and Psychopathology. 1999;11:785-803.

23. Fergusson Dm, Horwood LJ. Alcohol abuse and crime: A fixed-effects regression analysis. Addiction. 2000;95:1525-1536.

24. Menard S, Mihalic S. The tripartite conceptual framework in adolescence and adulthood: Evidence from a national sample. Journal of Drug Issues. 2001;31:905-939.

25. Swahn Mh, Donovan Je. Correlates and predictors of violent behavior among adolescent drinkers. Journal of Adolescent Health. 2004;34:480 492.

26. Wei Eh, Loeber R, White Hr. Teasing apart the developmental associations between alcohol and marijuana use and violence. Journal of Contemporary Criminal Justice. 2004;20(2):166-183.

27. Felson $\mathrm{Rb}$, Teasdale $\mathrm{B}$, Burchfield $\mathrm{Kb}$. The influence of being under the influence. Journal of Research in Crime \& Delinquency. 2008;45:119-141.

28. White Hr, Tice Pc, Stouthamer-Loeber M, et al. Illegal acts committed by adolescents under the influence of alcohol and drugs. Journal of Research in Crime and Delinquency. 2002;39(2):131-152.

29. Chen Cy, O’Brien Ms, Anthony Jc. Who becomes cannabis dependent soon after onset of use? epidemiological evidence from the United States: 2000-2001. Drug Alcohol Depend. 2005;79(1):11-22. 
30. Perkonigg A, Pfister H, Hofler M, et al. Substance use and substance use disorders in a community sample of adolescents and young adults: incidence, age effects and patterns of use. European Addiction Research 2006;12(4):187-196.

31. Behrendt S, Wittchen Hu, Höfler M, et al. Transitions from first sub-stance use to substance use disorders in adolescence: is early onset associated with a rapid escalation? Drug Alcohol Dependence. 2009;99(1-3):68-78.

32. Hoakena Pns, Stewartb Sh. Drugs of abuse and the elicitation of human aggressive behavior. Addict Behav. 2003;28(9):1533-1554.

33. Compton Wm, Thomas Yf, Stinson Fs, et al. Prevalence, correlates, disability, and comorbidity of DSM-IV drug abuse and dependence in the United States: results from the national epidemiologic survey on alcoho and related conditions. Arch Gen Psychiatry. 2007;64(5):566-576.

34. Diala Cc, Muntaner C, Walrath C. Gender, occupational, and socioeconomic correlates of alcohol and drug abuse among U.S. rural, metropolitan, and urban residents. Am J Drug Alcohol Abuse. 2004;30(2):409-428.

35. Lauren K, Whiteside Ml, Ranney St, et al. The overlap of youth violence among aggressive adolescents with past-year alcohol use-A latent class analysis: aggression and victimization in peer and dating violence in an inner city emergency department sample. $J$ Stud Alcohol Drugs. 2013;74(1):125-135.

36. Green, Km, Doherty Ee, Zebrak Ka, et al. Association between adolescent drinking and adult violence: evidence from a longitudinal study of urban african americans. J Stud Alcohol Drugs. 2011;72(5):701-710.

37. Rothman Ef, Stuart Gl, Greenbaum Pe, et al. Drinking style and dating violence in a sample of urban, alcohol-using youth. $J$ Stud Alcohol Drugs. 2011;72(4):555-566.

38. Brady Ss, Tschann Jm, Pasch La, et al. Violence involvement, substance use, and sexual activity among mexican american and european american adolescents. $J$ Adolesc Health. 2008;43(3):285-295.

39. Ali B, Swahn Mh, Sterling Kl. Attitudes about violence and involvement in peer violence among youth: Findings from a high-risk community. J Urban Health. 2011;88(6):1158-1174.

40. Cunningham Rm, Whiteside Lk, Chermack St, et al. Dating violence: Outcomes following a brief motivational interviewing intervention among at-risk adolescents in an urban emergency department. Acad Emerg Med. 2013;20(6):562-569.

41. Volpe Em, Hardie Tl, Cerulli C. Associations among depressive symptoms, dating violence, and relationship power in urban, adolescent girls. $J$ Obstet Gynecol Neonatal Nurs. 2012;41(4):506-518.

42. Blum Rw, Beuhring T, Shew Ml, et al. The effects of race/ethnicity, income, and family structure on adolescent risk behaviors. Am J Public Health. 2000;90(12):1879-1884.

43. Hsieh CC, Pugh Md. Poverty, income inequality, and violent crime: A meta-analysis of recent aggregate data studies. Criminal Justice Review. 1993;18(2):182-202.

44. Choi Y, Harachi Tw, Gillmore Mr, et al. Are multiracial adolescents at greater risk? Comparisons of rates, patterns, and correlates of substance use and violence between monoracial and multiracial adolescents. Am J Orthopsychiatry. 2006;76(1):86-97.

45. McNulty Tl, Bellair Pe. Explaining racial differences in adolescent violence: Structural disadvantage, family well-being and social capital. Justice Quarterly. 2003;20(1):1-31.

46. Haynie D1, Silver E, Teasdale B. Neighborhood characteristics, peer networks, and adolescent violence. J Quant Criminol. 2006;22(2):147169.
47. White Hr, Lee C, Mun Ey, et al. Developmental co-occurrence of alcohol use and persistent serious violent offending among African American and Caucasian young men. Criminology. 2012;50(2):391-426.

48. Gardner M, Roth J, Brooks-Gunn J. Sport, exercise, and performance psychology. 2011;1(S):19-37.

49. Temple J, Freeman Jr D. Dating violence and substance use among ethnically diverse adolescents. J Interpers Violence ol. 2011;26(4):701718 .

50. Stephens T, Braithwaite R, Turner J. Determinants of violent problem behavior among adolescent detainees in Georgia, U.S.A. International Journal of Prisoner Health. 2011;7(2/3):53-60.

51. Mardia Kv. Applications of some measures of multivariate skewness and kurtosis in testing normality and robustness studies. Sankhyā: The Indian Journal of Statistics. 1974;36:115-128.

52. Bonomo Y, Coffey C, Wolfe R, et al. Adverse outcomes of alcohol use in adolescents. Addictio. 2001;96(10):1485-1496.

53. Bonomo Y, Bowes G, Coffey C, et al. Teenage drinking and the onset of alcohol dependence: a cohort study over seven years. Addiction. 2004;99(12):1520-1528.

54. Chassin L, Pitts S, Prost J. Binge drinking trajectories from adolescence to emerging adulthood in a high-risk sample: Predictors and substance abuse outcomes. J Consult Clin Psychol. 2002;70(1):67-78.

55. Chou Ps, Pickering Rp. Early onset of drinking as a risk factor for lifetime alcohol-related problems. British Journal of Addiction. 1992;87:11991204.

56. Li F, Duncan T, Hops H. Examining developmental trajectories in adolescent alcohol use using piecewise growth mixture modeling analysis. J Studies Alcohol. 2001;62(2):199-201.

57. DeWit D, Adlaf Em, Offord Dr, et al. Age at first alcohol use: A risk factor for the development of alcohol disorders. Am J Psychiatry. 2000;157(5):745-750.

58. McGue M, Iacono Wg, Legrand L, et al. Origins and consequences of age at first drink. Alcohol Clin Exp Res. 2001;25(8):1156-1165.

59. Sartor Ce, Lynskey Mt, Heath Ac, et al. The role of childhood risk factors in initiation of alcohol use and progression to alcohol dependence. Addiction. 2006;102(2):216-225.

60. Biederman J, Wilens T, Mick E, et al. Psychoactive substance use disorders in adults with attention deficit hyperactivity disorder (ADHD): effects of ADHD and psychiatric comorbidity. Am J Psychiatry. 1995;152(11):16521658.

61. McManus M, Alessi Ne, Grapentine Wl, et al. Psychiatric disturbance in serious delinquents. Journal of American Academy of Child Psychiatry. 1984;23(5):602-615.

62. Lewis Do, Shanok Ss. The use of a correctional setting for follow-up care of psychiatrically disturbed adolescents. Am J Psychiatry. 1980;37(8):953955.

63. Cohen R, Parmelee Dx, Irwin L, et al. Characteristics of children and adolescents in a psychiatric hospital and a corrections facility. Am Acad Child Adolesc Psychiatry. 1990;29(6):909-913.

64. Lewis Do, Pincus J, Lovely R, et al. Biopsychosocial characteristics of matched samples of delinquents and non-delinquents. Journal of American Academy of Child and Adolescent Psychiatry. 1987;26(5):744-752.

65. Bailey S, Tarbuck P. Recent advances in the development of screening tools for mental health in young offenders. Current Opinion in Psychiatry. 2006;19(4):373-377. 
66. Stephens T, Holliday Rc. Suicide ideation and risk for HIV among juvenile offenders in Georgia. Int J Adolesc Med Health. 2014;26(1):137-143.

67. Braithwaite R, Conerly Rc, Robillard Ag, et al. Alcohol and other drug use among adolescent detainees. Journal Of Substance Use. 2003;8(2):126131

68. Stephens T, Holliday Rc, Jarboe J. Self-Reported ecstasy (MDMA) use and past occurrence of sexually transmitted infections (STIs) in a cohort juvenile detainees in the USA. J Community Health. 2015;40(2):308-313.

69. Medina KL, McQueeny T, Nagel BJ, et al. Prefrontal cortex volumes in adolescents with alcohol use disorders: unique gender effects. Alcohol Clin Exp Res. 2008;32(3):386-394

70. Walker EF, Sabuwalla Z, Huot R. Pubertal neuromaturation, stress sensitivity, and psychopathology. Dev psychopathol. 2004;16(04):807824

71. Clark DB, Thatcher DL, Tapert SF. Alcohol, psychological dysregulation, and adolescent brain development. Alcoholism: Clinical and Experimental Research. 2008;32(3):375-385.

72. Habeych ME, Charles PJ, Sclabassi RJ, et al. Direct and mediated associations between P300 amplitude in childhood and substance use disorders outcome in young adulthood. Biological Psychiatry. 2005;57(1):76-82
73. Swanson JW, Swartz MS, Van Dorn RA, at al. Comparison of antipsychotic medication effects on reducing violence in people with schizophrenia. $\mathrm{Br} J$ Psychiatry. 2008;193(1):37-43.

74. Crystal S, Olfson M, Huang C, et al. Broadened use of atypical antipsychotics: safety, effectiveness, and policy challenges. Health Affairs. 2009;28(5):w770-781.

75. Grunebaum MF, Mann JJ. Safe Use of SSRIs in young adults: how strong is evidence for new suicide warning? pediatric suicide rates increased in 2003-04 after the black-box warning, which has now been extended to patients age 18 to 24. Current Psychiatry. 2007;6(11):26.

76. Mann JJ, Emslie G, Baldessarini RJ, et al. ACNP Task Force report on SSRIs and suicidal behavior in youth. Neuropsychopharmacology. 2006;31(3):473-492.

77. Jagodic HK, Agius M, Pregelj P. Psychopharmacotherapy prescription and suicidal behaviour. Psychiatria Danubina. 2013;25(2): 324-328

78. Centorrino F, Goren JL, Hennen J, et al. Multiple versus single antipsychotic agents for hospitalized psychiatric patients: case-control study of risks versus benefits. American Journal of Psychiatry. 2014;161(4):700-706.

79. Fazel S, Zetterqvist J, Larsson H, et al. Antipsychotics, mood stabilisers, and risk of violent crime. The Lancet. 2004;384(9949):1206-1214. 